\title{
Wine Ageing in Oak Barrel: Effect of Toasting Process
}

\author{
Chira $\mathrm{K}^{1,2,3 *}$, González-Centeno $\mathrm{MR}^{1,2,3}$ and Teissedre $\mathbf{P L}^{1,2}$ \\ ${ }^{1}$ Univ. de Bordeaux, ISSVV, EA 4577 Unité de recherche OENOLOGIE, F-33882 Villenave d'Ornon, France \\ ${ }^{2}$ INRA, ISVV, USC 1366 OENOLOGIE, F-33882 Villenave d'Ornon, France
}

${ }^{3}$ Tonnellerie Nadalié, 99 Rue Lafont, 33290 Ludon-Médoc, France

Submission: October 23, 2016; Published: November 15, 2017

"Corresponding author: Chira K, Université de Bordeaux Institut des Sciences de la Vigne et du Vin, Unité de recherche Oenologie, EA 4577, USC 1366 INRA, IPB 210, chemin de Leysotte CS 5000833882 Villenave d'Ornon cedex, France, Email: kleopatra.chira@u-bordeaux.fr

\begin{abstract}
The effect of the degree of toasting of barrels used in wine ageing on the extraction pattern of ellagitannins, volatile compounds and sensory profile was investigated. A detailed study based on seven different commercial barrel toastings was performed with a Merlot wine being in contact with barrels for 12 months. Specific toasting techniques like watering process and toasting head pieces enhanced vanillin, oak lactones extraction and eugenol degradation respectively. Wine matured in Medium Toast was characterized with more vanilla flavour, wine being in Light Toast barrels was perceived less sweet and at the same time bitter and more astringent than the other samples. Astringency intensified significantly with ellagitannins concentration. When other factors like wine origin and winemaking process were compared with toasting effect, even if barrel toasting along with winemaking process/or wine matrix notably influenced significantly both chemical and sensory wine profile, ellagitannins concentration was mostly conditioned by the toasting process.
\end{abstract}

Keywords: Oak; Barrel; Ageing; Ellagitannins; Toasting; Astringency; Bitterness

\section{Introduction}

Since the 17th and 18th centuries, barrels have been used for ageing wines. During the maturation process, several physicochemical reactions occur, such as extraction of wood components, and interactions between wood components and wine. As a result of different reactions wine chemical composition and sensory characteristics, visual aspect (colour and limpidity), taste and flavor are improved. Oak wood consists principally of macromolecules like cellulose, hemicellulose, lignin [1] and extractives, primarily ellagitannins, and some aromatic precursors [2]. Hydrolysable tannins (ellagitannins) in oak heartwood represent $10 \%$ of the dry weight and their oral sensation was described as astringent at relatively low threshold concentrations spanning from 0.2 to $6.3 \mu \mathrm{mol} / \mathrm{L}$ whereas a bitter taste was perceived at threshold concentrations between 410 and $1650 \mu \mathrm{mol} / \mathrm{L}[3]$.

More recent studies confirmed that ellagitanin levels participate in astringency and bitterness intensity [4,5]. The main volatile compounds susceptible to migration from oak wood to wine are the cis and trans isomers of $\beta$-methyl- $\gamma$ octalactone, furfural and its derived compounds, phenolic aldehydes such as vanillin, syringaldehyde and volatile phenols such as eugenol, guaiacol, and ethyl- and vinylphenols [6]. The sensory impact of these compounds is largely based on their threshold perception without taking into account the possibility of sensory interactions with other volatiles derived from oak or from microbial activity during the maturation phase. Thus, threshold data [7] suggest that vanillin, eugenol and the isomers of $\beta$-methyl- $\gamma$-octalactone have a strong influence on wine aroma, while furfural and 5-methylfurfural have, on their own, no more than a minor impact.

At the same time, some factors like the age of the wood, time and seasoning technique, and the heat treatment of oak wood influence wine chemical composition [8-10]. In order to give form to the barrels the wood is heated. Usually, three types of toasting are used for oak barrels: light, medium and medium plus. This stage is considered as the most important because during heating treatment a severe wood chemical composition modification is induced and new chemical compounds are generated. For example when a Merlot wine has been aged during one year in barrels represented different toasting treatments, its chemical and sensory composition is impacted [11].

Different toasting temperatures either common that varied from $47^{\circ} \mathrm{C}$ for the Light Toast (LT), $57^{\circ} \mathrm{C}$ for Medium Toast (MT) barrels and $62{ }^{\circ} \mathrm{C}$ for the Medium Plus Toasted (MT+) barrels or specific toasts like Noisette Toast $\left(52^{\circ} \mathrm{C}\right)$, Medium Toast with Watering (MT AA), Medium Toast with Toasted Heads (MT TH) 
and Medium Plus Toast with Watering (MT+ AA) were used. Light toasted presented higher ellagitannin concentrations comparing to Medium toasted, Noisette barrels being toasted 6 minutes less than Medium Toasted and at a lower temperature, elicited more ellagitannins. Wine aged in barrels that were submitted a watering process during toasting (MT AA) as well as wine matured in barrels with toasting head pieces (MT TH) presented lower ellagitannin concentration. Meaning that toasting, pyrolysis and hydrothermolysis will degrade wood constituents like ellagitannins, which are easily hydrolyzed $[12,13]$.

Concerning the volatile compounds that are more implicated in the overall woody aroma like eugenol, vanillin and whisky lactone, these compounds are also significantly influenced by toasting. Eugenol, responsible for clove-like aroma is found in higher quantities when the toasting process is realized at 57 ${ }^{\circ} \mathrm{C}$. Toasting up to $62{ }^{\circ} \mathrm{C}$ (case of $\mathrm{MT}+$ and $\mathrm{MT}+\mathrm{AA}$ ) results in its degradation. Wine aged in MT barrels contains more eugenol in comparison with wine aged in MT TH barrels, meaning that toasting the barrel head pieces enables eugenol degradation. LT barrels released more oak lactones compounds to wine than the toasted barrels, due to the thermo-degradation of these heatsensitive compounds or their loss by volatilization when the oak wood is subjected to high temperatures or even charring. Both MT AA and MT+AA barrels liberate more lactones than MT and $\mathrm{MT}+$, meaning that watering process during toasting may enhance lactones extraction $[4,5]$.

Vanillin concentration is considered to reflect the intensity of the toasting process (Vanillin is primarily formed in wood during toasting process). Noisette barrel elicited more vanillin than MT and LT barrel with the latter extracting less than the former, suggesting that a toasting temperature between LT and MT improves vanillin extraction. Medium Toast with watering (MT AA) extracts more vanillin than MT, indicating that watering process also influenced vanillin extraction. Hence up to a certain degree of toasting wood constituents, lignins and hemicelluloses will be degradated and will contribute to raise the volatile compound level [14] and at the same time some techniques during toasting like watering seems to control better lignins and hemicellulose degradation with the consequence to increase certain volatile compounds like vanillin. The sensory evaluation of the same wines demonstrated that wines from MT TH and Noisette barrels were characterized with more intense vanilla aroma than the other wines which could be associated to their higher vanillin levels.

Regarding, overall woody aroma, significant differences have been found between LT and MT wine whereas among the different Medium toast processes (Noisette, MT, MT AA, MT+, $\mathrm{MT}+\mathrm{AA}$ ) judges found slight differences with MT, Noisette being characterized more intense. Wine contact with Noisette and MT barrels led to an increase in spicy aromas, but when wine is in contact with LT barrels spicy flavor is slightly reduced. The sample matured in LT barrels was perceived less sweet and at the same time bitter and more astringent than the other samples that can be attributed to their higher ellagitannin levels. Thus, toasting strongly influences the oak wood chemical composition, which in turn will influence wine ageing.

On the whole the results discussed above clearly suggest that the same initial wine will obtain a different profile depending strongly on the barrel toasting that has been aged in. What would happen if identical barrels with different medium toastings (MT, MT AA, Noisette) were used in different wine countries cellars (France, Italy, USA) to mature the corresponding wine for 12 months? In this case the interaction between barrel toasting and wine matrix played an important role in the extraction rate of volatile compounds from oak wood during ageing [15]. However the toasting method clearly influenced more than the wine origin the ellagitannin content which in turn had sensory consequences on the final wine as both astringency and bitterness were positively and significantly linked to ellagitannin contents $(\mathrm{p}<$ 0.05).

Wine aged in Noisette barrels outstanded clearly from the others for its greatest ellagitannin content, followed by MT AA and MT wines. Among the other parameters studied (oak wood and fruity volatile composition), barrel toasting along with the alcoholic degree and/or wine matrix notably influenced the whiskey lactones extraction rate from oak wood. The effect of the barrel toasting was also evaluated in comparison with Malolactic Fermentation (MLF)-container [16]. Keeping the Medium toast barrels (MT, MT AA, Noisette) for 12 months wine ageing, another study aimed to estimate the impact of both Malolactic Fermentation (MLF)-container and barrel toasting on ellagitannins, aromatic composition and sensory attributes of two sets of Cabernet Sauvignon wine: one in which MLF and ageing were carried out in oak barrels, and another where MLF was performed in tanks previous to barrel ageing.

On the whole, the interaction between MLF-container and barrel toasting influenced notably wine chemical and sensory characteristics. Nevertheless, regardless of the MLF-container, ellagitannin composition was influenced more by the toasting method. From an olfactory point of view, judges' preference can be classified by the barrel toasting with MT and Noisette toastings found as the most preferred. The above studies have shown also that the type of oak barrel toasting employed for ageing has a strong influence principally on the ellagitannin profile of the wines aged in them. As a result, such influence cannot be ignored, considering the role that these compounds can play in colour stabilization of red wines, in the formation of new anthocyano-ellagitannin pigments [17] and in wine astringency and bitterness depending on their concentration $[3,11]$, as well as the different chemical and biological activities that they exhibit [18].

\section{Conclusion}

The choice of barrel toasting process is determining for the wine quality. Wines with different characteristics can be obtained from the same base wine, after 12 months of ageing, in relation 
to the kind of toasting process used (notably on specific aromas profile and concentrations). Whatever is the wine origin or the winemaking process, ellagitannin concentration is essentially influenced by barrel toasting which in return may have an impact on wine visual and gustative quality.

\section{Aknowledgements}

The authors gratefully thank Nadalié cooperage for the financial support and for providing the oak wood.

\section{References}

1. Le Floch A, Jourdes M, Teissedre PL (2015) Polysaccharides and lignin from oak wood used in cooperage: Composition, interest, assays: A review. Carbohydrate Res 417: 94-102.

2. Guichard E, Masson G, Fournier N, Puech JL (1995) Stereoisomers of $\beta$-Methyl- $\gamma$-Octalactone. II. Contents in the Wood of French (Quercus robur and Quercus petraea) and American (Quercus alba) Oaks. Am J Enol Vitic 46(4): 424-428.

3. Glabasnia A, Hofmann T (2006) Sensory-directed identification of taste-active ellagitannins in American (Quercus alba L.) and European oak wood (Quercus robur L.) and quantitative analysis in bourbon whiskey and oak-matured red wines. J Agric Food Chem 54(9): 33803390.

4. Chira K, Teissedre PL (2013) Extraction of oak volatiles and ellagitannins compounds and sensory profile of wine aged with French winewoods subjected to different toasting methods: Behaviour during storage. Food Chem 140(1-2): 168-177.

5. Chira K, Teissedre PL (2013) Relation between volatile composition, ellagitannin content and sensory perception of oak wood chips representing different toasting processes. Eur Food Res Tech 236(4): 735-746.

6. Cerdán TG, Goñi DT, Azpilicueta CA (2004) Accumulation of volatile compounds during ageing of two red wines with different composition. J Food Eng 65(3): 349-356.

7. Boidron JN, Chatonnet $P$ (1988) Influence du bois sur certaines substances odorantes des vins (Effects of wood on aroma compounds of wine). Connaiss Vigne Vin 22: 275-294.

8. Cerdán TG, Rodríguez MS, Ancín AC (2002) Volatile composition of aged wine in used barrels of French oak and of American oak. Food Res Int 35(7): 603-610.
9. Jordão AM, Ricardo-da-Silva JM, Olga L, Adams A, Demyttenaere J, et al. (2006) Volatile composition analysis by solid-phase microextraction applied to oak wood used in cooperage (Quercus pyrenaica and Quercus petraea): Effect of botanical species and toasting process. J Wood Sci 52(6): 514-521.

10. Fernandez DSB, Cadahía E, Conde E, García-Vallejo MC (1999) Evolution of phenolic compounds of Spanish oak wood during natural seasoning. First results. J Agric Food Chem 47(4): 1687-1694.

11. Chira K, Teissedre PL (2014) Chemical and sensory evaluation of wine matured in oak barrel: effect of oak species involved and toasting process. Eur Food Res Tech 240(3): 533-547.

12. Cadahìa E, Varea S, Muñoz L, Fernández DSB, García-Vallejo MC (2001) Evolution of ellagitannins in Spanish, French, and American oak woods during natural seasoning and toasting. J Agric Food Chem 49(8): 36773684.

13. Matricardi L, Waterhouse AL (1999) Influence of toasting technique on color and ellagitannins of oak wood in barrel making. Am J Enol Vitic 50(4): 519-526.

14. Gimenez MR, Lopez Garcia DLSH, Villalon Mir M, Quesada GJ, Lopez MMC (1996) Influence of wood heat treatment, temperature and maceration time on vanillin, syringaldehyde, and gallic acid contents in oak wood and wine spirit mixtures. Am J En Vitic 47(4): 441-446.

15. González-Centeno MR, Chira K, Teissedre PL (2016) Ellagitannin content, volatile composition and sensory profile of wines from different countries matured in oak barrels subjected to different toasting methods. Food Chem 210: 500-511.

16. González-Centeno MR, Chira K, Teissedre PL (2017) Comparison between Malolactic Fermentation Container and Barrel Toasting Effects on Phenolic, Volatile, and Sensory Profiles of Red Wines. J Agric Food Chem 65(16): 3320-3329.

17. Chassaing S (2010) Physicochemical studies of new anthocyanoellagitannin hybrid pigments: About the origin of the influence of oak C-glycosidic ellagitannins on wine color. Eur J Org Chem (1): 55-63.

18. Sylla T, Pouységu L, Da Costa G, Deffieux D, Monti JP, et al. (2015) Gallotannins and Tannic Acid: First Chemical Syntheses and in vitro Inhibitory Activity on Alzheimer's Amyloid $\beta$-Peptide Aggregation. Angew Chem Int Ed Engl 54(28): 8217-8221.
This work is licensed under Creative Commons Attribution 4.0 License DOI: 10.19080/ARTOAJ.2017.12.555847
Your next submission with Juniper Publishers will reach you the below assets

- Quality Editorial service

- Swift Peer Review

- Reprints availability

- E-prints Service

- Manuscript Podcast for convenient understanding

- Global attainment for your research

- Manuscript accessibility in different formats

( Pdf, E-pub, Full Text, Audio)

- Unceasing customer service

Track the below URL for one-step submission https://juniperpublishers.com/online-submission.php 